\title{
Universiteit
}

Leiden

The Netherlands

\section{Language attitudes and ideologies on linguistic diversity} Albury, N.J.; Schalley, A.C.; Eisenchlas, S.A.

\section{Citation}

Albury, N. J. (2020). Language attitudes and ideologies on linguistic diversity. In A. C. Schalley \& S. A. Eisenchlas (Eds.), Handbooks of Applied Linguistics (pp. 357-376). Berlin/Boston: De Gruyter Mouton. doi:10.1515/9781501510175-018

Version:

Publisher's Version

License:

Licensed under Article 25fa Copyright Act/Law (Amendment Taverne)

Downloaded from: $\quad$ https://hdl.handle.net/1887/3220772

Note: To cite this publication please use the final published version (if applicable). 


\section{Language attitudes and ideologies on linguistic diversity}

Beyond the ever-intriguing faculty of humans to acquire and creatively use their linguistic resources, the maintenance of linguistic diversity is ultimately a social phenomenon. Our field acknowledges that a home language, in this case taken to mean a minority or heritage language - such as of immigrant or Indigenous groups whose language differs from the majority but is used in some homes - has a greater chance of ongoing vitality, and indeed transmission, if it is prized and valued by society more broadly, whether this be for social, cultural or economic reasons. Conversely, we may have cause for concern if a language is marginalized through a discursive association with, for example, socioeconomic immobility or oppositional identities. Language behaviours - and the maintenance of home languages in a society - are therefore dialectically related to social, cultural, political and economic circumstances. It is in this perspective that language attitudes and ideologies are pertinent themes in home language research. These, as lines of inquiry, put a spotlight on how individuals, families and communities feel about linguistic diversity and indeed the ongoing use - or not of specific home languages. With that in mind, this chapter specifically discusses the relevance of researching language attitudes and ideologies vis-à-vis linguistic diversity within the broader framework of home language research. It begins by outlining the place of researching language beliefs in applied linguistics. The chapter then especially seeks to delineate and problematize ideologies and attitudes in theoretical terms, and highlights the theoretical opportunities and challenges that they, as conceptual resources, bring to home language inquiry. In doing the above, the chapter draws on an international library of research on home languages.

\section{Language ideology and attitudes in applied linguistics}

Since the 1960s with the seminal works of Lambert (1967), Lambert et al. (1960), Hymes (1962, 1972) and Labov (1966), linguists have generally accepted that real-life language behaviours - such as the realization and management of linguistic diversity in the home - are not divorced from their social contexts. Instead, the application of linguistic resources, as they manifest from our cognitive faculties, are mediated through societal norms, beliefs and dispositions. Silverstein (1985: 220) later offered a similar argument that language and society are "irreducibly dialectic" whereby effective meaning-making, through the range of semiotic resources made available by a 
language, is only made possible through culturally-situated intersubjectivities. The notion is that language behaviours are guided by what a broader community sees as appropriate and expected linguistic practice. Labov's (1966) seminal and oft-cited investigation of New York accents proved this upon detailing phonological shifts which denoted membership to social class and engendered speech stereotypically associated with that class. It is therefore the case that as much as humans are socialized into linguistic competence, so too are we socialized into social, cultural and political constraints and expectations of how language is or should be used. In such thinking, a community's broader milieu - laden with its social, cultural and political views about what is good and what is not good about the social world - informs sociolinguistic practices. For the purposes of this volume, these practices include choices in homes to use and transmit specific languages. A particularly salient influence in that decision-making process is how individuals and communities feel about home languages - and multilingualism more generally - as these feelings manifest in language ideologies and attitudes.

Ideologies and attitudes are pertinent in linguistic research because their impacts can be felt widely across societal domains. Governments pursue language policies that favour certain languages over others based in ideologies of nation-building and perceptions of what constitutes a nation's ethnolinguistic identity (Spolsky 2004). Iceland, for example, is preoccupied with preserving its language to be as close as possible to the ancient Norse language of the Icelandic Sagas. So strong is this concern that the government routinely formulates and promulgates Icelandic neologisms as alternatives to English loanwords and is even resurrecting ancient Icelandic morphology. What is more, public attitudes to this ideological work are by and large very supportive (Hilmarsson-Dunn and Kristinsson 2010). However, this preoccupation means Iceland is largely silent on its emerging multilingualism subsequent to increased immigration, especially from Eastern Europe, under Iceland's regionally integrated economic arrangements. Whereas supporting home languages and their speakers through minority-medium instruction or welfare services has preoccupied western states (cf. May 2014), an Icelandic apprehension about diversity - and the impact this may have on the status of Icelandic - means the state is yet to catch-up with European counterparts on matters of language rights. For example, whereas a child of Polish labour migrants in continental Europe might access education that as an epistemological starting point anticipates multiculturalism and multilingualism in the classroom, her peer in Iceland most likely cannot (Jónsdóttir and Ragnarsdóttir 2010). Iceland's dominant discourse and beliefs about Icelandic as an endangered language therefore have tangible impacts on the status, and broader public perceptions of, home languages.

The impacts of language ideologies and attitudes can also be especially pronounced in the grassroots outside the purview of government but where beliefs hold such power that they nonetheless regulate home language maintenance. Hornberger's (1988) seminal work in Quechua communities of Peru found grassroots ideologies that 
value Spanish/Quechua multilingualism, with attitudes that on the one hand pedestalized Spanish for socioeconomic mobility but on the other hand positioned Quechua as the preferred code for fostering solidarity. These beliefs guided sociolinguistic arrangements and would be instrumental in determining the future role of Quechua in the face of Spanish as a language of economy (see also Mayer et al. this vol.). My own research amongst Indigenous and non-Indigenous New Zealanders (Albury 2016) revealed ideological enthusiasm, shared by Indigenous and non-Indigenous youths alike, for Māori language revitalization. Fostering the language was seen as pivotal to postcolonial reconciliation, to naming the landscape authentically, and to the formation of a contemporary, quintessentially Kiwi identity. Nonetheless, the Māori language was also seen to hold limited instrumental value. In turn, these New Zealand youths offered attitudes that they are more inclined to study languages that are notionally "more useful", such as Mandarin or French, rather than partake in Māori language revitalization.

Language ideologies and attitudes can therefore regulate linguistic diversity at the macro and micro level. Spolsky (2004: 14) even describes community beliefs about language as "policy with the manager left out" because beliefs can - in the absence of any formal law or policy - nonetheless guide a raft of linguistic matters from who gets language rights and who does not, whether someone chooses to study another language and indeed which language, and what language is spoken to whom and in what situations. However, this also raises the pertinent question - one which in my experience muddles junior and senior researchers alike - of what in fact the difference is between language attitudes and ideologies. Applied linguistic literature is prone to using the terms interchangeably, and without necessarily clarifying the theoretical understandings they presuppose when applying these terms (Kroskrity 2004). Some scholars circumvent the dilemma of delineating them by instead capturing ideologies and attitudes collectively as language beliefs, and do so with the perspective that their delineation is perhaps unnecessary or impossible (Spolsky 2004; England 2017). I, however, feel that their delineation is necessary and possible for the purposes of robust scholarship in home language studies. This now becomes the focus of this chapter. What follows is my attempt to explain why that is so, beginning with a discussion of language ideology.

\section{Language ideology}

The field is awash with competing conceptualizations of what in fact amounts to a language ideology. What unites the different perspectives, however, is the premise that language ideologies are social constructions, that they are products of the human experience and its attempts to regulate social life, that they are shared by some collective, and that they provide a framework of biases about the linguistic 
world or some part of it. This framework then becomes a reference point for constructing discourses, ideas, dispositions and decisions about language.

Language ideology research has its genesis in the pioneering linguistic anthropological works of Hymes (1977) and of Blom and Gumperz (1972). At a time when their work was at the margins of both linguistics and of anthropology, they argued that local language practices and variation, as they manifest within speech communities, might be best understood through metalinguistic beliefs. Whereas theoretical linguists have rightly argued that languages are all equal, the social turn in linguistics would prove that social realities are more complex. Whether in societies, communities, or homes, beliefs about language - for example about how languages should be used, where they should be used, and their status mean that different varieties and behaviours are perceived through social filters. They may index different socioeconomic standings or political affiliation, they may diverge from or conform to agreed linguistic norms, or they may challenge notions of ethnic belonging or national cohesion. Adding to this, Silverstein (1979: 193) offered the view that language ideologies are "sets of beliefs about language articulated by users as a rationalization or justification of perceived language structure and use".

It pays to note that a postmodern perspective might warn that ideology research unnecessarily essentializes beliefs and the groups of people deemed to hold these beliefs. Indeed, it is precarious to make definitive correlations between specific groups and specific beliefs, for example that all teachers of bilingual school X uphold ideology $\mathrm{Y}$ on multilingualism, or that family $\mathrm{Z}$ does or does not value bilingualism. In this regard, language ideology research runs the risk of deemphasizing individual agency - such as how dominant ideologies can be contested, negotiated, (re)interpreted or (re)articulated - in favour of consistency between beliefs and groups of people which would make for neat and tidy research. The question also arises as to what in fact constitutes a collective such that an ideology can be attributed to it. While it is clear that society or social groups may produce and share specific language ideologies, do smaller groups such as households - also constitute a collective that can foster and execute its own ideologies or are they too small, as individual groups, for the purposes of robust ideology research? These questions remain unanswered and their treatment largely depends on individual research enterprises. This is not to say that ideology research is fraught with epistemological anxieties. It is important to be cognizant that language ideologies can exist in parallel and in competition within a given collective. It is also important to note that what constitutes a collective is open for negotiation, that within collectives there can be divergent or minority views, and that approaches to ideology research ought to be made explicit. On this last point, language ideology research can be largely seen as either descriptive or critical. 


\subsection{A descriptive orientation}

A descriptive orientation to language ideology seeks to research, identify and understand the shared beliefs of some collective - where the collective is defined by the researcher - about how language arrangements ought to be and why the collective feels this way. Rumsey (1990: 346), for example, described language ideologies as "shared bodies of commonsense notions about the nature of language in the world". The starting point, as such, is the local contexts and belief systems that make sense of why communities feel and behave the way they do, as these help to contextualize and rationalize ideologies. This was exemplified in Sandel's (2003) work in Taiwan. There, dominant ideologies in the home vis-à-vis the relationship between Mandarin as the community's majority language and Hokkien as a home language were in part rationalized by public histories. Sandel's argument was that language ideologies about the relationship, as they manifested in actual family language practices, could be dialectically traced to different discourses and policies over time that had been sponsored by the Taiwanese government. This political history was essential background to understanding shared commonsense notions about language as they are held in the community and in homes.

For others, descriptive ideological research has especially focused on intersubjectivities within a community that need not be expressed, but nonetheless form an unspoken collective sociocognitive template for dealing with language. For example, Blommaert (2006: 510) defines a language ideology as "the unspoken assumptions that, as some kind of 'social cement', turn groups of people into communities, societies, and cultures". In other words, some beliefs about language are so normative that they need not attract metadiscourse, unless of course this normativity is somehow challenged. Schiffman (1996) speaks of linguistic culture as a conceptual tool which, for our purposes, can be considered a descriptive orientation to language ideology. Rather than analyzing language ideologies through epistemological lenses from the outside, researching linguistic culture means obtaining an emic view of the collective "ideas, values, beliefs, attitudes, prejudices, myths, religious strictures, and all other cultural 'baggage' that speakers bring to their dealings with language from their culture" (Schiffman 1996: 112). Schiffman's approach was inspired by his ethnographic work in India's Tamil Nadu. He discovered what he believed to be a linguistic culture that did not expect him as an outsider to learn spoken Tamil, and that any Tamil he did speak ought to have been of the formal written variety. So entrenched was this intersubjective belief that Schiffman was approached by local political leaders to cease his ethnographic research. Another item of baggage that can contribute to a linguistic culture is religion. From a theoretical linguistic perspective, little difference may be noticed between spoken Hindi, Urdu and Punjabi, but their delineation as separate languages is a local fait accompli on the basis of religion rather than linguistics. Whereas Hindi is associated with Hinduism and uses Devanagari 
script, Urdu is associated with Islam and uses Perso-Arabic script, and Punjabi is associated with Sikhism and uses Gurumukhi script (Schiffman 1996).

At this juncture, I have added folk linguistic knowledge to the mix of constituents that may contribute to language ideology (Albury 2017). The "unspoken assumptions", "social cement”, "sets of beliefs about language", and "shared bodies of commonsense notions" that amount to language ideology - as noted above - can also include shared claims of knowledge. I take a Foucauldian view whereby knowledge is socially constructed - and not necessarily empirically reliable - and each instantiation of knowledge contributes to developing or challenging a regime of truth based in the values, beliefs, and world views (Foucault 1980). Language ideology can therefore comprise claims not only of what is desirable, but also of what is true and what is not true about the linguistic world, regardless of the accuracy of such claims. This is because it is discourses, rather than any preordained reality, that construct perceived truths. This especially matters, of course, when claimed knowledge is used to decide whether or not bilingualism is cognitively and socially beneficial, and how it should be managed in the home, in that claimed knowledge in linguistics may help determine whether a home language is at all transmitted (see also Purkarthofer this vol.). My argument is, therefore, that what is claimed by a collective to be true about the linguistic world warrants scholarly attention because this also guides local language discourses, ideas and language policy decisions. Placing local knowledge at the centre of ideology research is also postmodern in that it helps us to decolonize linguistics. It does not herald academic knowledge as a final authority, but validates local knowledge - as part of the human experience - as informing local truths and as guiding local realities. Under such thinking, the academy is not the only source of legitimate truths, if legitimacy is measured by local influence rather than academic qualification. In the case of non-western scholarship, it also helps us to transcend epistemological assumptions about language that may be covertly woven into our research. For example, Fishman (1990) offered pioneering theories about how to stop and reserve language shift in Indigenous communities. His lens did, however, harbour western values, including a direct relationship between language and identity and the ideological salience of literacy. These are being questioned in postmodern terms within emic-oriented language ideology work (cf. Romaine 2006). Placing local ideologies of language at the centre of local sociolinguistic research avoids colonizing local phenomena with epistemologically foreign interpretations and gives voice to knowledge paradigms that do not traditionally feature in mainstream scholarship.

With the preeminence of Western perspectives in sociolinguistics, an oftdescribed language ideology is the monolingual assumption (Cross 2011). The belief here is that individuals and societies - of which the United States is a popular example - are normatively monolingual, irrespective of actual linguistic diversity. Hence the joke "If a man who speaks three languages is trilingual and a man who speaks two languages is bilingual, what do you call a man who speaks only one language? American”. Jokes aside, this ideology has been central to the formation of nation- 
states supported by the standardization of official languages. The genesis of such ideology is in modernism - with its interest in cohesion and uniformity - and in assumptions that ethnicity, language and statehood are directly correlated. Naturally, no state is monolingual in practice and the ideology attracts scholarly discussion. Transnationalism, migration and Indigenous activism mean that even in states that ideologically claim to be monolingual, multilingual realities are increasingly visible. Where homogeneity is challenged, the otherwise unscripted monolingual assumption manifests in debates about linguistic orders. In the case of northern Norway, Hiss (2013) discusses the panicked and seemingly racist discourses that emerged among some communities in Troms $\varnothing$ when their town was tagged to be included within the official Indigenous Sámi zone and therefore formally bilingual in recognition of Sámi as an official language. The taken-for-granted Norwegianness of Tromsø had, through political assembly, become open for debate. This created a stage for ideological debate about the linguistic future of Tromsø that harboured a monolingual assumption at its core.

In contrast, and in the spirit of looking beyond the West, I would argue that a multilingual assumption may be a pertinent ideology on the ground in societies where diversity is normative and where routinely drawing on different language varieties is unmarked. This has been the case in my research on sociolinguistic identities, practices and ideologies in multilingual and multicultural Malaysia (Albury 2018). For those living in a society that hosts only a slight Malay majority, a plethora of Chinese, Indian and Indigenous home languages, as well as prestige for English and Arabic for socioeconomic and religious purposes respectively, day-to-day communication is resourceful. It is defined by meaning-making and fluid multilingual behaviours akin to translanguaging (Li 2011). The resultant ideology, as it has especially been expressed by Malaysian youths, sees individual multilingualism as unmarked. Indeed, a ChineseMalaysian university student I encountered in Penang was at pains to impress upon me the normativity of individual multilingualism in Malaysia and to contrast this with local ideologies in the West. She explained "it's like we are either a bilingual or multilingual, we are not monolingual". This is also the case in the Yanyuwa culture in Australia's Northern Territory, where husbands and wives speak different dialects but with a passive understanding of each other's variety (Bradley 2011). In India, daily lives may cross Hindi as a national language, English as a working language, and one or more local languages (Kalra 2017). The monolingual assumption can therefore be contrasted with the multilingual assumption of other societies.

\subsection{A critical orientation}

Language ideologies lend themselves not only to description but also to critique because they are sites of power negotiations between speakers on the basis of different languages and the perceived values they hold. A critical approach to language 
ideology is grounded in criticizing the sociolinguistic world for its inequalities, its injustices, and its systems of domination. For example, Moita-Lopes (2014) refers to Portuguese as an internationalized language and the principled need to reconstruct, for the purpose of late modernity, what Portuguese even means as a term and ideology. Doing so would be inclusive of identities, innovations and language changes from Latin America and to be critical of the Eurocentrism - and its implicit power relation embedded in a history of conquest and colonization - that is subsumed within Portuguese as a label applied to language realities in Brazil. The goal, in any critical orientation, is to identify such explicit or implicit inequalities and ultimately liberate the marginalized "from the circumstances that enslave them" (Horkheimer 1982: 244). A critical orientation therefore continues the legacy of the pioneering critical social theoretical work of the Frankfurt school (Martin 1996), of Foucault's (1980) concern for social stratifications, and of Bourdieu's (1991) notions of linguistic capital - and language as symbolic power - that advantages some and disadvantages others. Central to these approaches, for our purposes, is an understanding that certain languages come to hold - by virtue of social intervention greater value or prestige than others (see also Liddicoat this vol.).

On this last point, critical language ideology research has now become widely premised in political economy (cf. Gal 1989; Ricento 2015; Piller and Cho 2013). Political economy is understood to be "the study of the social relations - particularly the power relations - that mutually constitute the production, distribution, and consumption of resources, including communication resources" (Mosco 2017: 13). The starting point is, as Muehlmann and Duchene (2007: 98) explain, that the "expansion of nation-state economies, and the simultaneous strengthening of the private sector, has also resulted in greater articulations between local, national, and supranational identities, as goods, people, and information begin moving across boundaries at a new pace". This has created a new world order, for those in capitalist democracies, that is typified by experiences of globalization including international connectivity through media, migration and liberalized economics. This means that local lives need not be only local, and that languages - and indeed linguistic diversity - become increasingly valorized - or devalorized in the case of home languages - in terms of their efficiency and place within the global order. Oftentimes this is to the detriment of smaller languages and their transmission in homes.

Political economy - especially capitalism, late modernity and neoliberalism - is therefore a framework for discovering and exposing linguistic hegemonies and inequalities subsequent to such valorization. Especially vocal, for example, are Skutnabb-Kangas and Phillipson (2010) who argue that globalization, and the worldwide spread of English that this encompasses, is killing off other languages. Controversially, they add that English and its speakers commit linguistic genocide and linguistic imperialism, such that globalization amounts not only to homogenization but also to the coordinated spread of Anglo-American culture. They fear that "the 'manifest destiny' that colonial Americans arrogated to themselves has been 
explicitly linked, since the early nineteenth century, to English being established globally" (Skutnabb-Kangas and Phillipson 2010: 80) and therefore to displacing other languages. Heller and Pavlenko (2010) also approach language ideology through political economy. They propose that the value of specific languages is tied to the linguistic marketplace in capitalist, neoliberal terms, and that this can devalue home languages and their use. For example, the instrumental value of English, but also of other majority languages that are seen to advance socioeconomic mobility, may overshadow the perceived value of home languages that afford less socioeconomic mobility. The concern then is that the world's smaller languages are denied capital, such that their very survival is unduly jeopardized. This creates a need to study language ideologies, vis-àvis economics and the power relations they create between languages. While these discussions are typically framed in theoretical terms, the rubber hits the road in otherwise bilingual communities, schools and homes where the language of tradition becomes pitted against the language of economy and connectivity, and where parents seek to balance the transmission of culture and heritage with the perceived socioeconomic opportunity inherent to dominant languages.

Political economy therefore necessitates choice between some languages and others on economic lines, and in this respect the critical approach has offered vocabulary that is core to contemporary language ideology research. Two examples that are especially salient are the notion of language hierarchies and of language prestige, whereby a community attributes specific value or salience to a certain language or variety above others for cultural, economic or social reasons. This builds on seminal works on diglossia which sees varieties of a single language stratified for their high or low status (Ferguson 1959), and on the expansion of diglossia to include the relative roles and statues given to different languages in a multilingual society. Pervasive examples can be found in postcolonial societies where colonial languages have assumed power and prestige over Indigenous languages. New Zealand is a worthy example in that it is ideologically bicultural and bilingual in the interests of postcolonial reconciliation, but multicultural and multilingual in practice as a result of liberal immigration policy. English is hierarchized above minority languages, but a hierarchy of home languages also seemingly exists. Greater prestige is afforded to Māori as the Indigenous language of the islands, and less prestige to Pacific languages as immigrant languages (de Bres 2015). While prestige can be traced to histories, colonization, education departments and language laws, language ideology becomes especially dynamic in cases of covert prestige. Some languages or varieties may not enjoy official or highculture status, but may be valued for expressing specific, potentially marginalized identities. This has been the case, for example, for Tunisian Arabic. Standard Arabic and French, with their high-status and correlations to religion and culture, generally hold overt prestige and occupy official domains. Nonetheless, Tunisian Arabic indexes Tunisian heritage and culture and has attracted a covert prestige for the expression of an in-group, quintessentially Tunisian, identity in the postcolonial pan-Islamic world (Stevens 1983; S'hiri 2002). 
However, a problem with a political economic orientation to critical language ideology is that it is often applied when analyzing language in a global context with global dynamism. Doing so, however, assumes the operation of free markets or uncensored digital mobility. These, as elements of a new world order, are often taken to be a reality for all. This is not the case for language users outside the reach of competitive capitalism. North Korea is as an obvious example of a closed market with little domestic exposure to English through a transnational economy, meaning the ubiquity of English as ideology and practice, and the alarmist discourse this might entail, hold less clout. In a different example, Iran heavily censors access to digital platforms that represent globalization, such as Facebook and YouTube, meaning contemporary understandings of language practices as increasingly networked and transnational through the affordance of connectivity in technology can be problematized. Instead, linguistic capital and political economy in North Korea and Iran have more domestic orientations than the more internationalized orientations of linguistic capital and political economy in, for example, Europe or North America. As a theoretical presupposition, political economy may therefore be primarily valuable when critiquing language arrangements in free, capitalist environments where languages indeed function as transnational commodities in transnational spaces. What is more, language contact studies show us that political economy is not qualified, in epistemological and cultural terms, to critique all local language arrangements. In the Amazon and in Indigenous Australia, for example, linguistic diversity is in some communities more strongly regulated by cultures of exogamy (Epps 2005) than by economics. Because a critical orientation to language ideology is oriented in exposing and rectifying inequalities, it also presupposes egalitarianism as a social ideal, democracy as a necessary goal, and ethnic rights as a universal value. These are, however, anti-structuralist ideas from the West and not necessarily ones valued in nonWestern cultures (Irvine and Gal 2000). We must therefore be cautious in universally applying critical theory in language ideology research. For example, linguistic egalitarianism as a manifestation of multicultural policy is a political, social and economic value in Singapore whereby Malay, Mandarin and Tamil are afforded equal status. In neighbouring Malaysia, which hosts a similar diversity, local political culture has hierarchized race and language under a system of ethnocratic pluralism. There, Malay language and culture are codified as definitive of Malaysia within an ideology that constructs local citizens of Chinese and Indian ancestry as disloyal visitors. A critical orientation to language ideology may wish to criticize Malaysia, but it would do so by presupposing Western values are well-placed to criticize Malaysian values.

The critical approach, and its emphasis on linguistic equality, also tends to assume that personal and collective identities are intrinsically related to language. In practice, however, this relationship is complex rather than a fait accompli, and demands critical problematization in itself (cf. May 2000). For example, my research (Albury 2016) in New Zealand suggests that a direct ideological correlation between language and ethnic identity, as is familiar to European societies, may not exist or 
is at least contestable in the case of Māori. This seems entirely plausible if we agree that identity is relational and we know that beyond dialectal differences, Māori New Zealanders were monolingual prior to the arrival of the British. Instead, Māori sooner identify across tribes in respect to the landscape and ancestry. Language plays a backseat role to other values in identity formation. This all means that applying critical theory outside the cultures from which it epistemologically evolved may at best overlook local value systems, or at worst advance western academic imperialism. This is not to undo the value of critical approaches, but instead to be reflective that critical theory epistemologically biases a western-centric world view.

Other salient notions in language ideology are the standard language and linguistic purism. Specific language varieties can be codified as the official language of the state, and their grammars, lexica and orthographies are managed centrally. In turn, a collective comes to endorse that variety as normative and correct, including potentially within homes and schools, such that non-conforming behaviours become marked as incorrect or undesirable. In France, standard French was heralded as vital to fostering national cohesion, while divergent practices were seen to threaten unity (Spolsky 2004). In communities that have seen language shift - for example in diaspora communities or Indigenous societies that suffered colonization - language maintenance is often marked by purism in the pursuit of self-determination and the restoration of what was lost (Dorian 1994). As language ideologies, standard languages and linguistic purism may primarily be the domain of sociolinguists concerned with intra-language behaviours rather than with multilingualism per se. However, their impacts can be detrimental on home languages undergoing revitalization in homes. Zuckermann and Walsh (2011), for example, call on Indigenous communities undertaking language revitalization to embrace rather than reject the hybrid linguistic practices of Indigenous language learners for the sake of language maintenance. Their point is that purism and standards constrict revitalization by ignoring natural language change, interferences that are common to second language acquisition, and the anxieties that purist discourses can inspire.

Not adhering to expected linguistic norms is known to result in linguistic discrimination (see also Annamalai and Skuttnab-Kangas this vol.). Rickford and King (2016) offer a compelling analysis of linguistic discrimination under America's standard language ideology. This, they found, can even impede the criminal justice system, as was the case of Jeantel, a witness to a murder trial. She gave evidence in non-standard English, but doing so led the court to deem her evidence unreliable. Her home language was, it was decided, unfit for civil purposes. The standard language ideology was such that it marginalized Jeantel, by way of negative attitudes towards her language, in a domain where equality and justice are supposedly core pursuits. In this situation, language ideology manifested into associated attitudes. This calls on us to also consider what amounts to language attitude and how this is, or is not, different to language ideology. 


\section{Language attitudes}

In our daily lives we confront attitudes, as they are expressed by those connected to us physically and virtually, to various social matters including language. Log on to the Australian franchise of Student Flights, and one sees the company's provocative language attitudes woven into its destination marketing. "What's that? You speak French? Excuse me while I remove my pants. The votes are in and it's unanimous: French is the sexiest language in the history of ever". For the same website Russian, on the other hand, is apparently "quite an impressive purr of linguistic chaos. Someone once described Russian speech as existing somewhere between the roar of a walrus and a Brahms lullaby. Sounds about right” (Rigg 2013).

Attitudes are, therefore, subjective. They come to sociolinguistics from social psychology, whereas language ideology scholarship finds its genesis in anthropology. Reliable working definitions of attitude include that it is a "psychological tendency that is expressed by evaluating a particular entity with some degree of favor or disfavor" (Eagly and Chaiken 1993: 1), and that attitude is "a disposition to react favorably or unfavorably to a class of objects" (Sarnoff 1970: 279). In the examples above, the perceived sexiness of French is favourable, whereas the attractiveness of Russian is dubious. However, social psychological responses to linguistic diversity need not only concern specific languages per se. Attitudes may be formed, for example, in respect to a language policy (Baker 2006). In Catalonia, González-Riaño et al. (2019) found that youths seemingly held more positive attitudes towards Catalan than their parents who were more likely to hold positive attitudes towards Spanish. This speaks not only to the support of the younger generation for Catalan language maintenance, but no doubt also to broader sociopolitical biases in the context of Catalan's vexed political situation. In the case of Morocco, Marley (2004) found positive attitudes to French/Arabic bilingual education with the view that these attitudes contributed to the success of that language policy and the maintenance of both languages in Moroccan society. In such cases, attitudes become especially pertinent, and indeed influential in the actual realization of societal multilingualism in places undergoing social and political transformation. In post-Hong Kong, the vexed relationship between Cantonese and Mandarin synonymizes competing political interests under the gradual handover of Hong Kong to China (cf. Lai 2011). Attitudes to the use of Mandarin or Cantonese can be seen as indexing attitudes to Hong Kong's political future, whereby Beijing allegedly supports Hong Kong shifting to Mandarin while most Hong Kong homes remain fervently Cantonese. Attitudes might also form in respect to multilingualism in itself. My work in Malaysia (Albury 2018) has, for example, uncovered attitudes to the multilingual linguistic landscape, linguistic diversity in Malaysian homes and schools, and even to multilingualism as a cognitive phenomenon. These attitudes contributed to the construction of discourses that supported, questioned, or discouraged the maintenance of local diversities. It is through this relationship between attitudes and discourse that attitudinal research is firmly part of the sociolinguistic research enterprise. 
Whereas ideologies provide a blueprint for sociolinguistic ideas and behaviours, language attitudes only ever evaluate a specific phenomenon or occurrence. That is to say, language ideologies are a socially-constructed reference point for how things ought to function in society, whereas language attitudes are an evaluation of whether, in what way, and to what extent, a specific language, language practice, or other language matter, is favourable. For example, the monolingual assumption discussed earlier may presuppose the normativity of individual and social multilingualism. An attitude, on the other hand, is a person's dispositional reaction to a specific stimulus. Imagine the stimulus is, for example, the use of more than one language in society in a place where the monolingual assumption reigns. An associated attitude, held by a person who subscribes to the monolingual assumption, may be that multilingual practices in a specific context or domain are undesirable. Depending on who holds this view, this attitude can influence the maintenance or not of bilingualism in local contexts. In this regard, it could be argued that ideologies tend to be ill-defined whereas attitudes may be more definable. This is because ideologies are typically unmarked and subject to social construction whereas attitudes are dispositions vis-à-vis defined stimuli.

Language attitude research attracts both quantitative and qualitative approaches. Ideological research on the other hand is fundamentally qualitative - making use of discoursal and pragmatic analysis - to the exception of quantitative tools, such as corpus analysis, that help to locate and quantify ideology-laden discourse in texts. Classic attitudinal work is quantitative by tasking participants to rate their levels of agreement to specific notions which serve as stimuli for soliciting a language attitude. This was also the case in my research about the relationship between English and Māori in postcolonial New Zealand. Some 1,300 university students were asked to identify, on a five-point continuum from strongly disagree to strongly agree, how they felt about statements including "revitalising te reo Māori is a good thing, even if it costs time and money" and "it would be better if everyone in the country spoke one language in all situations" (Albury 2016). The total sum of responses would therefore provide a data set on attitudinal trends vis-à-vis these core policy topics. Other quantitative approaches may use a semantic differential scale, whereby participants rate to what extent they endorse certain evaluations of a specific linguistic matter. For example, the matched guise technique might ask participants to indicate how intelligent, attractive or kind a speaker is based on that speaker's speech in a specific language or accent (cf. Eisenchlas and Tsurutani 2011). The innovation is that attitudes to language are inferred through evaluations of a speaker, and this is controlled for by the participants also evaluating the speech of a local native speaker but not knowing that this is actually a bilingual who produces both examples.

In qualitative research, attitudes might be identified within discourse or conversational data as stances towards specific topics (Jaffe 2009) where participants use evaluative adjectives to describe specific phenomena or premise their statements as personal opinions. This was the case, for example, in Obojska's (2017) analysis of 
online metalinguistic talk among Polish teenagers in Norway whose discourses revealed various attitudes towards Polish as a heritage language and to Norwegian as the majority language, including feelings of linguistic shame and obligation that regulate participation in the different language groups, and even attitudes towards the language attitudes of others. It is also the case in research on discourses amongst Serbian users towards Cyrillic and Latin as Serbia's two co-official scripts. Attitudes include, on the one hand, that Cyrillic is valuable because it is intrinsically Orthodox and therefore Serbia's most authentic script, and on the other hand that Cyrillic is undesirable because it indexes Serbian ethnonationalism and conservatism (Jovanović 2018).

Like ideologies, attitudes can be described or be analyzed through a critical lens, but a core distinction is that attitudes need not be held by a collective whereas ideologies are shared beliefs. Attitudes can therefore be the phenomena of individuals and need not constitute shared "commonsense notions" (Rumsey 1990: 345). That is not to say that the same or a similar attitude cannot be shared. To the contrary, attitudes may be held by groups of people who share a world view and researching the prevalence of a particular attitude helps to take the "attitudinal temperature" of the public on specific language issues. The point, however, is that attitudes - with their genesis in psychology - are by definition evaluative dispositions constructed at the point of their expression.

To this extent, language attitudinal research is not without empirical problems. Because attitudes are immediate responses to specific stimuli, their cognitive nature means they may be better described as "an internal state of readiness" (Fasold 1984: 147) at a particular moment in time. These states of readiness may or may not be communicated in such a way they can always be accessed confidently, and may be subject to change. This also means that ideologies, as systematic belief systems that construct social cohesion, are more durable than attitudes. This is because attitudes may be informed by a wide variety of sources such as mood, motivation, individual understanding, ego and personality (Ajzen 2005). Attitudes can also be a logical byproduct of what an individual believes to be true about the (socio)linguistic world, such that assumed knowledge becomes a resource for developing an attitude. For example, a pervasive attitude in New Zealand against making Māori language a compulsory subject in schools did not originate in any negative disposition towards the language. Instead, it originated in an assumption that the teacher workforce is too weak to support such policy implementation, entirely separate to matters of linguistics (Albury 2017). Taking an attitude at face value, without further investigation, risks misinterpreting social psychological data. 


\section{Conclusion: A nexus between language ideology and language attitudes?}

So far this chapter has delineated attitudes from ideology for the purposes of home language research. However, the stage they share in sociolinguistics, their often interchangeable use, and their common interest in community perspectives, all imply that they are nonetheless related. The genesis of a specific attitude can indeed sometimes be traced to a systematic language ideology. This dialectical relationship has oftentimes been an empirical conclusion in my own research into discourses about linguistic diversity. Specifically, an individual's attitude may be the obvious articulation of an ideology to which the individual subscribes. For example, Figure 1 shows how that dialectal relationship has manifested within discourses about societal multilingualism in Malaysia. In the first example, a group of youths from the ethnic Malay majority were tasked to discuss the desirability of Malaysia - to which their own heritage language is indigenous - now being multilingual as a result of historic migrations. They were also asked to reflect on the intermittent calls being made by the
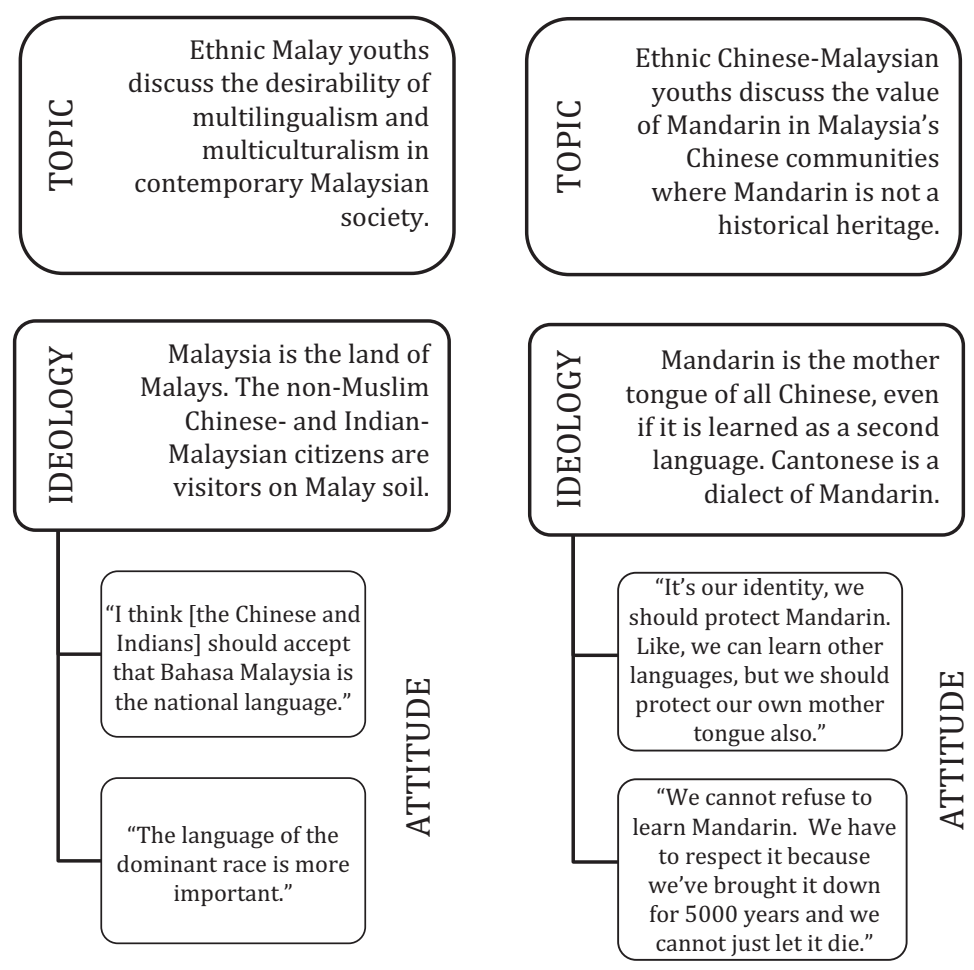

Figure 1: A dialectic relationship between language ideology and language attitudes. 
Chinese and Indian minorities for linguistic rights. The second example concerns discussions amongst a group of ethnic Chinese-Malaysian youths about what role Mandarin should play in their community, given that Mandarin was not an historic heritage language brought to Malaysia through migration but is routinely studied as a second language. In both cases, Figure 1 gives examples of different attitudes expressed by individuals being consistent with the prevailing ideology that was identified within that group's discourse more broadly.

Just as commonly, however, ideologies and attitudes may be incongruent. An ideology of a collective may sooner be an idealized world view that does not translate into individual attitudes that advance that ideology. A recurring example of this incongruence results from what May (2014) might call a tension between the Local and the Global. Here, the premise is that in the context of globalization and neoliberalism with their tendencies towards the homogenization of language and culture - ethnic groups may share a concern for the maintenance of their languages in local communities, schools and homes. However, individual attitudes towards actively participating in that ideology - such as by committing to heritage language learning or raising children bilingually - may be less enthusiastic. That is to say, one may subscribe to an ideology that is good for the collective but not to a congruent attitude if it is seen to place burdens on the individual. For example, research from Ireland shows that Irish holds high ideological value in constructing a sense of nationhood contextualized by memories of English rule. Nonetheless, attitudes to learning and using the language are oftentimes ambivalent, while attitudes to other European languages are positive by seeing them as instrumental and cosmopolitan (Atkinson and Kelly-Holmes 2016). The issue is that socioeconomic ambition and the utility associated with fluency in dominant cultures and languages demotivates individuals and families from committing to home languages. It can also be the case that other cognitive influences simply override the influence of any ideology that might encourage linguistic diversity. For example, the magnitude of linguistic anxiety, negative language learning experiences, or perceived aptitude may result in negative attitudes towards active participation in home language use, acquisition, revitalization or transmission (cf. Sevinç and Dewaele 2018; Sevinç this vol.) despite ideological support for home language development.

I therefore conclude with the view that a nexus between language ideology and language attitudes indeed exists, but it is a complex one that may be both dialectic and incongruent. My interpretation is that they are indeed related, but that how they diverge is as salient as their commonalities. They have different disciplinary and epistemological geneses and offer scholarship different - albeit related - theoretical and methodological concepts. It is therefore futile to seek to theorize attitudes and ideologies as in all cases harmoniously complementary. Nonetheless, and as long as language is seen as a social phenomenon, ideology and attitudes will remain essential concepts for investigating grassroots engagement with matters of linguistic diversity and the multitude of factors that guide the maintenance and development or not, of languages in the home. 


\section{References}

Ajzen, Icek. 2005. Attitudes, personality, and behavior. Milton Keynes: Open University Press.

Albury, Nathan John. 2016. Defining Māori language revitalisation: A project in folk linguistics. Journal of Sociolinguistics 20(3). 287-311.

Albury, Nathan John. 2017. The power of folk linguistic knowledge in language policy. Language Policy 16(2). 209-228.

Albury, Nathan John. 2018. Multilingualism and mobility as collateral results of hegemonic language policy. Applied Linguistics. 1-27. Online First. DOI: https://doi.org/10.1093/applin/ amy054

Annamalai, E. \& Tove Skutnabb-Kangas. this vol. Social justice and inclusiveness through linguistic human rights in education.

Atkinson, David \& Helen Kelly-Holmes. 2016. Exploring language attitudes and ideologies in university students' discussion of Irish in a context of increasing language diversity. Language and Intercultural Communication 16(2). 199-215.

Baker, Colin. 2006. Psycho-sociological analysis in language policy. In Thomas Ricento (ed.), An introduction to language policy: Theory and method, 210-228. Malden, MA: Blackwell.

Blom, Jan-Petter \& John Gumperz. 1972. Social meaning in linguistic structures: Code switching in Norway. In John Gumperz \& Dell Hymes (eds.), Directions in sociolinguistics, 407-434. Holt: Rinehart \& Winston.

Blommaert, Jan. 2006. Language ideology. In Keith Brown (ed.), Encyclopedia of language \& linguistics, 510-522. 2nd edn. Amsterdam: Elsevier.

Bourdieu, Pierre. 1991. Language and symbolic power. Cambridge: Harvard University Press.

Bradley, John. 2011. Yanyuwa: "Men speak one way, women speak another". In Jennifer Coathes \& Pia Pichler (eds.), Language and Gender: A Reader, 13-20. Malden, MA: Wiley-Blackwell.

Cross, Russell. 2011. Troubling literacy: Monolingual assumptions, multilingual contexts, and language teacher expertise. Teachers and Teaching 17(4). 467-478.

De Bres, Julia. 2015. The hierarchy of minority languages in New Zealand. Journal of Multilingual and Multicultural Development 36(7). 677-693.

Dorian, Nancy C. 1994. Purism vs. compromise in language revitalization and language revival. Language in Society 23(4). 479-494.

Eagly, Alice H. \& Shelly Chaiken. 1993. The psychology of attitudes. Fort Worth, TX: Harcourt Brace Jovanovich College Publishers.

Eisenchlas, Susana A. \& Chiharu Tsurutani. 2011. You sound attractive! Perceptions of accented English in a multi-lingual environment. Australian Review of Applied Linguistics 34(2). 216-236.

England, Neil. 2017. Developing an interpretation of collective beliefs in language teacher cognition research. TESOL Quarterly 51(1). 229-238.

Epps, Patience. 2005. Areal diffusion and the development of evidentiality: Evidence from Hup. Studies in Language. International Journal sponsored by the Foundation "Foundations of Language" 29(3). 617-650.

Fasold, Ralph. 1984. The sociolinguistics of society. Oxford: Blackwell.

Ferguson, Charles A. 1959. Diglossia. Word 15(2). 325-340.

Fishman, Joshua A. 1990. What is reversing language shift (RLS) and how can it succeed? Journal of Multilingual and Multicultural Development 11(1\&2). 5-36.

Foucault, Michel. 1980. Power/knowledge: Selected interviews and other writings, 1972-1977. Brighton: Pantheon.

Gal, Susan. 1989. Language and political economy. Annual Review of Anthropology 18(1). 345-367. 
González-Riaño, Xosé Antón, Alberto Fernández-Costales, Cecilio Lapresta-Rey \& Ángel Huguet. 2019. Language attitudes towards Spanish and Catalan in autochthonous and immigrant families in Catalonia: Analysing the correlation between student attitudes and their parents'. International Journal of Bilingual Education and Bilingualism 22(6). 754-767.

Heller, Monica \& Aneta Pavlenko. 2010. Bilingualism and multilingualism. In Jürgen Jaspers, JanOla Ostman \& Jef Verschueren (eds.), Society and language use, 71-83. Amsterdam \& Philadelphia: John Benjamins.

Hilmarsson-Dunn, Amanda \& Ari Páll Kristinsson. 2010. The language situation in Iceland. Current Issues in Language Planning 11(3). 207-276.

Hiss, Florian. 2013. Tromsø as a "Sámi Town"? - Language ideologies, attitudes, and debates surrounding bilingual language policies. Language Policy 12(2). 177-196.

Horkheimer, M. 1982. Critical theory. New York: Seabury Press.

Hornberger, Nancy. 1988. Language ideology in Quechua communities of Puno, Peru. Anthropological Linguistics 30(2). 214-235.

Hymes, Dell. 1962. The ethnography of speaking. In Thomas F. Gladwin \& William C. Sturtevant (eds.), Anthropology and Human Behavior, 3-53. Washington D.C.: Anthropological Society of Washington.

Hymes, Dell. 1972. Models of the interaction of language and social life. In John Gumperz \& Dell Hymes (eds.), Directions in sociolinguistics: The ethnography of communication, 35-71. New York: Holt, Rinehart \& Winston.

Hymes, Dell. 1977. Discovering oral performance and measured verse in American Indian narrative. New Literary History 8(3). 431-457.

Irvine, Judith T. \& Susan Gal. 2000. Language ideology and linguistic differentiation. In Paul V. Kroskrity (ed.), Regimes of language: Ideologies, polities, and identities, 35-83. Santa Fe: School of American Research Press.

Jaffe, Alexandra. 2009. Introduction: The sociolinguistics of stance. In Alexandra Jaffe (ed.), Stance: Sociolinguistic perspectives, 3-28. New York: Oxford University Press.

Jónsdóttir, Elsa S. \& Hanna Ragnarsdóttir. 2010. Multicultural education in Iceland: Vision or reality? Intercultural Education 21(2). 153-167.

Jovanović, Srđan M. 2018. Assertive discourse and folk linguistics: Serbian nationalist discourse about the cyrillic script in the 21st century. Language Policy 17(4). 611-631.

Kalra, Mani Bhasin. 2017. Preserving heritage languages through schooling in India. In Peter Perciles Trifonas \& Themistoklis Aravossitas (eds.), Handbook of research and practice in heritage language education, 1-18. Cham: Springer.

Kroskrity, Paul V. 2004. Language ideologies. In Alessandro Duranti (ed.), A companion to linguistic anthropology, 496-517. Oxford: Blackwell.

Labov, William. 1966. The social significance of speech in New York City. Washington, DC: Center for Applied Lingusitics.

Lai, Mee Ling. 2011. Cultural identity and language attitudes - into the second decade of postcolonial Hong Kong. Journal of Multilingual and Multicultural Development 32(3). 249-264.

Lambert, Wallace E. 1967. A social psychology of bilingualism. Journal of Social Issues 23(2). 91-109.

Lambert, Wallace E., Richard C. Hodgson, Robert C. Gardner \& Samuel Fillenbaum. 1960. Evaluational reactions to spoken languages. The Journal of Abnormal and Social Psychology 60(1). 44.

Li, Wei. 2011. Moment Analysis and translanguaging space: Discursive construction of identities by multilingual Chinese youth in Britain. Journal of Pragmatics 43(5). 1222-1235.

Liddicoat, Anthony J. this vol. Language policy and planning for language maintenance: The macro and meso levels. 
Marley, Dawn. 2004. Language attitudes in Morocco following recent changes in language policy. Language Policy 3(1). 25-46.

Martin, Jay. 1996. The dialectical imagination: A history of the Frankfurt School and the Institute of Social Research 1923-1950. Vol. 10. Berkley, Los Angeles: University of California Press.

May, Stephen. 2000. Uncommon languages: The challenges and possibilities of minority language rights. Journal of Multilingual and Multicultural Development 21(5). 366-385.

May, Stephen. 2014. Justifying educational language rights. Review of Research in Education 38(1). 215-241.

Mayer, Elisabeth, Liliana Sánchez, José Camacho \& Carolina Rodríguez Alzza. this vol. The drivers of home language maintenance and development in indigenous communities.

Moita-Lopes, Luiz P. 2014. Introduction: Linguistic ideology: How Portuguese is being discursively constructed in late modernity. In Luiz P. Moita-Lopes (ed.), Global Portuguese: Linguistic ideologies in late modernity, 1-26. New York: Routledge.

Mosco, Vincent. 2017. Political economy. In Toby Miller (ed.), The Routledge companion to global popular culture, 13-22. New York \& London: Routledge.

Muehlmann, Shaylih \& Alexandre Duchêne. 2007. Beyond the nation-state: International agencies as new sites of discourses on bilingualism. In Monica Heller (ed.), Bilingualism: A social approach, 96-110. London: Palgrave Macmillan.

Obojska, Maria A. 2017. "Are you so ashamed to come from Poland and to speak your mother tongue?" - Metalinguistic talk, identities and language ideologies in teenagers' interactions on ASKfm. Multilingual Margins 4(1). 27-39.

Piller, Ingrid \& Jinhyun Cho. 2013. Neoliberalism as language policy. Language in Society 42(1). 23-44.

Purkarthofer, Judith. this vol. Intergenerational challenges: Of handing down languages, passing on practices, and bringing multilingual speakers into being.

Ricento, Thomas. 2015. Political economy and English as a "global" language. In Thomas Ricento (ed.), Language policy and political economy: English in a global context, 27-47. Oxford \& New York: Oxford University Press.

Rickford, John R. \& Sharese King. 2016. Language and linguistics on trial: Hearing Rachel Jeantel (and other vernacular speakers) in the courtroom and beyond. Language 92(4). 948-988.

Rigg, Ashton. 2013. The world's sexiest languages. https://www.studentflights.com.au/travel-mag /2013/04/the-worlds-sexiest-languages (accessed 24 April 2019).

Romaine, Suzanne. 2006. Planning for the survival of linguistic diversity. Language Policy 5(4). 443-475.

Rumsey, Alan. 1990. Wording, meaning, and linguistic ideology. American Anthropologist 92(2). 346-361.

S'hiri, Sonia. 2002. Speak Arabic please!: Tunisian Arabic speakers' linguistic accommodation to Middle Easterners. In Aleya Rouchdy (ed.), Language contact and language conflict in Arabic: Variations on a sociolinguistic theme, 149-176. New York \& London: Routledge.

Sandel, Todd L. 2003. Linguistic capital in Taiwan: The KMT's Mandarin language policy and its perceived impact on language practices of bilingual Mandarin and Tai-gi speakers. Language in Society 32(4). 523-551.

Sarnoff, Irving. 1970. Social attitudes and the resolution of motivational conflict. In Marie Jahodaand and Neil Warren (eds.), Attitudes, 279-284. Harmondsworth: Penguin.

Schiffman, Harold. 1996. Linguistic culture and language policy. London: Routledge.

Sevinç, Yeşim. this vol. Anxiety as a negative emotion in home language maintenance and development. 
Sevinç, Yeşim \& Jean-Marc Dewaele. 2016. Heritage language anxiety and majority language anxiety among Turkish immigrants in the Netherlands. International Journal of Bilingualism 22 (2). 159-179.

Silverstein, Michael. 1979. Language structure and linguistic ideology. In Paul Clyne, William Hanks \& Carol Hofbauer (eds.), The elements, 193-248. Chicago: Chicago Linguistic Society.

Silverstein, Michael. 1985. Language and the culture of gender. In Elizabeth Mertz \& Richard Parmentier (eds.), Semiotic mediation, 219-259. Academic Press.

Skutnabb-Kangas, Tove \& Robert Phillipson. 2010. The global politics of language: Markets, maintenance, marginalization, or murder? In Nicholas Coupland (ed.), The handbook of language and globalization, 77-100. Malden, MA: Wiley-Blackwell.

Spolsky, Bernard. 2004. Language policy. Cambrige: Cambridge University Press.

Stevens, Paul B. 1983. Ambivalence, modernisation and language attitudes: French and Arabic in Tunisia. Journal of Multilingual and Multicultural Development 4(2-3). 101-114.

Zuckermann, Ghil'ad \& Michael Walsh. 2011. Stop, revive, survive: Lessons from the Hebrew revival applicable to the reclamation, maintenance and empowerment of Aboriginal languages and cultures. Australian Journal of Linguistics 31(1). 111-127. 